\title{
Effect of changes in intraocular pressure on the retinal microcirculation
}

T. J. FFYTGHE, G. J. BULPITT, E. M. KOHNER, D. ARGHER, AND G. T. DOLLERY

From the Wellcome Medical Ophthalmology Unit, Hammersmith Hospital, and Moorfields Eye Hospital, High Holborn

The development of fluorescein angiography has stimulated a great deal of interest in the vascular physiology of the retina and choroid by providing a method for examining different aspects of the ocular circulation in vivo. Of particular interest is the role of the blood supply to the optic disc in the production of field defects in glaucoma, and its . relationship to pathological disc cupping (Hayreh, I969, I970; Blumenthal, Best, Galin, and Toyofuku, I97I; Goldmann and Blok, 1971). A number of experiments in animals and man have been carried out to demonstrate the influence of acute and chronic rises in the intraocular pressure on the choroidal supply to the disc and peripapillary region (Blumenthal, Gitter, Best, and Galin, 1970; Swietliczko and David, 1970; Blumenthal, Best, and Galin, I97I). In these conditions of high intraocular pressure, whether pathological or experimental, several observations have been made on the accompanying reduction of blood velocity in the retinal arteries but, apart from the studies by Dollery, Henkind, Kohner, and Paterson (1968), little quantitative data exists on this relationship between altered perfusion pressure and retinal blood flow.

The present series of experiments was designed as an extension of the work of Dollery and his co-workers to investigate the changes in retinal blood flow velocity and retinal blood flow at different intraocular pressures, and to study the effects of measures used to treat retinal artery obstructions in man.

\section{Method}

Studies were carried out on nine young pigs aged between 6 and 12 weeks with weights ranging from $\underset{\omega}{N}$ I 3 to $28 \mathrm{~kg}$. The experimental procedure described in a previous publication (ffytche, Bulpitt, Archer, $\mathcal{O}^{2}$ Kohner, and Dollery, 1973) was followed. Anaesthesia was induced with intravenous 5 per cent. 6 sodium thiopentone and continued after tracheal intubation by further thiopentone injections through a leg vein catheter. Ventilation was maintained using a Palmer pump and continuous? recordings of the pulse and blood pressure were obtained through a P6o catheter inserted into the aorta via the femoral artery and connected to a Devices $\mathrm{M}_{4}$ recorder. Arterial $\mathrm{pO}_{2}, \mathrm{pCO}_{2}$, and $\mathrm{pH}$ were monitored throughout the experiments. 
The eye was prepared for photography by dilating the pupil with cyclopentolate (Mydrilate I per cent.) eye drops. A modified Flieringa ring was sutured to the sclera at the limbus and attached by four sutures to a ring of micromanipulators; by this method it was possible to position the eye with a minimum of distortion or traction on the globe. A 25 gauge needle was inserted into the anterior chamber at the limbus and connected by a catheter and a three-way tap to a strain-gauge transducer and the Devices $\mathrm{M}_{4}$ recorder, with the third outlet of the tap communicating with a saline reservoir (Fig. I). The intraocular pressure could be altered by raising or lowering this reservoir along a scale calibrated in mm.Hg, and the pressure was recorded continuously and controlled by the reservoir; this was found to be necessary since a high pressure declined rapidly without it, either because of the normal outflow facility of the angle of the anterior chamber or because of leakage around the intracameral needle.

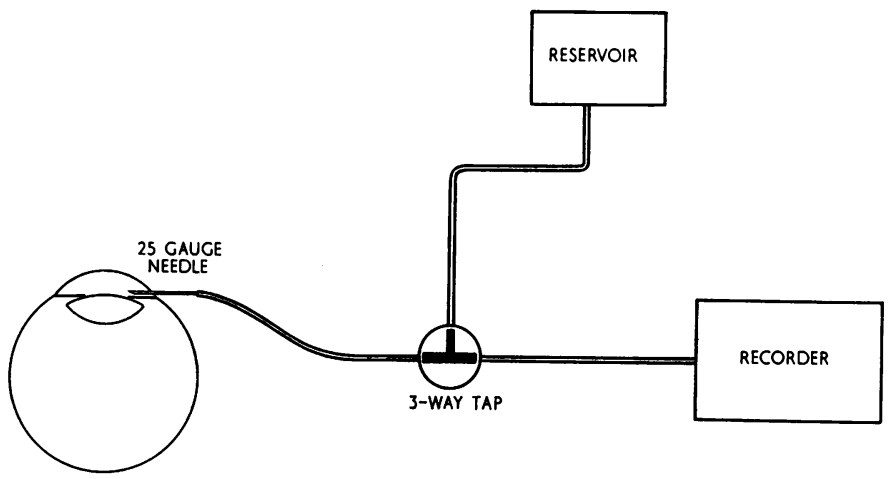

FIG. I Diagram of experimental procedure to control and record intraocular pressure

For photography about $0.5 \mathrm{ml}$. 10 per cent. fluorescein sodium was injected into the common carotid artery via a cannula introduced retrogradely through an ear artery and ciné angiograms were taken, using a Bolex $\mathrm{H} 16 \mathrm{~mm}$. camera mounted vertically on the Zeiss fundus camera. A measured frame speed of 30 frames per second on Ilford Mark V film was used with the insertion of the Baird Atomic $\mathrm{B}_{4}$ exciting filter and the Zeiss 300976 barrier filter in the light pathway of the camera.

\section{Techniques of measurements}

\section{(I) Vessel diameters}

All measurements were made from the ciné film negatives, using a microscope with a micrometer scale in the ocular head. Total internal diameters of the vessels were taken to be the width of the fluorescein column when the vessel was full (Bulpitt, Dollery, and Kohner, 1970). With the micrometer method of measurement, the standard deviation of a single artery of approximately 100 $\mu$ was $2 \cdot 4 \mu$ (ffytche and others, 1973).

\section{(2) Dye front velocity}

Frame-to-frame analysis of the fluorescein dye front along selected retinal arteries was used to measure blood flow velocity (Bulpitt and Dollery, 1970) and the diameter of the vessel was determined at either end of the section under examination. A Vanguard Motion Analyser was used and dye front velocity expressed in arbitrary units per second.

\section{(3) Volume flow}

The volume flow was calculated from measurements of arterial diameter and dye front velocity as described previously (ffytche and others, I973), the same assumptions being made about the velocity profile; the measurements were expressed in arbitrary volume units per minute. 


\section{(4) Perfusion pressure}

Studies were made on the relationship between the perfusion pressure and blood flow velocity, arterial diameter, and volume flow. Measurements of ophthalmic artery pressure cannot be made directly in pigs by ophthalmodynamometric techniques since the retinal arteries do not derive from a single central artery but arise from cilio-retinal arteries linked to the choroidal circulation (Rootman, 1971). The perfusion pressure was therefore calculated by subtracting the intraocular pressure from the mean blood pressure (MBP), defined as the diastolic $+\mathrm{I} / 3$ systolic/diastolic difference, no adjustment being made for the drop in blood pressure between the aorta and the ophthalmic artery.

\section{Results}

The response of the retinal circulation to raised intraocular pressure depended on the experimental procedure that was followed. The main variables were the duration of the raised pressure and the speed at which it was attained; these conditions were standardized in each series of experiments.

\section{(1) Initial blood flow velocity on raising the intraocular pressure}

If the intraocular pressure was raised rapidly and a fluorescein angiogram performed within $30 \mathrm{sec}$, the blood flow velocity altered without substantial changes in retinal arterial diameters. Fig. 2 shows that in these conditions a linear relationship existed between the blood flow velocity and the perfusion pressure and this held down to the point where visible pulsatile flow in the arteries made velocity measurements inaccurate. The results in four arteries (three animals) with diameters ranging from 147 to $55 \mu$ are demonstrated. The four regression lines are given in Fig. 2, and the regression coefficients were significant at the I per cent. level.

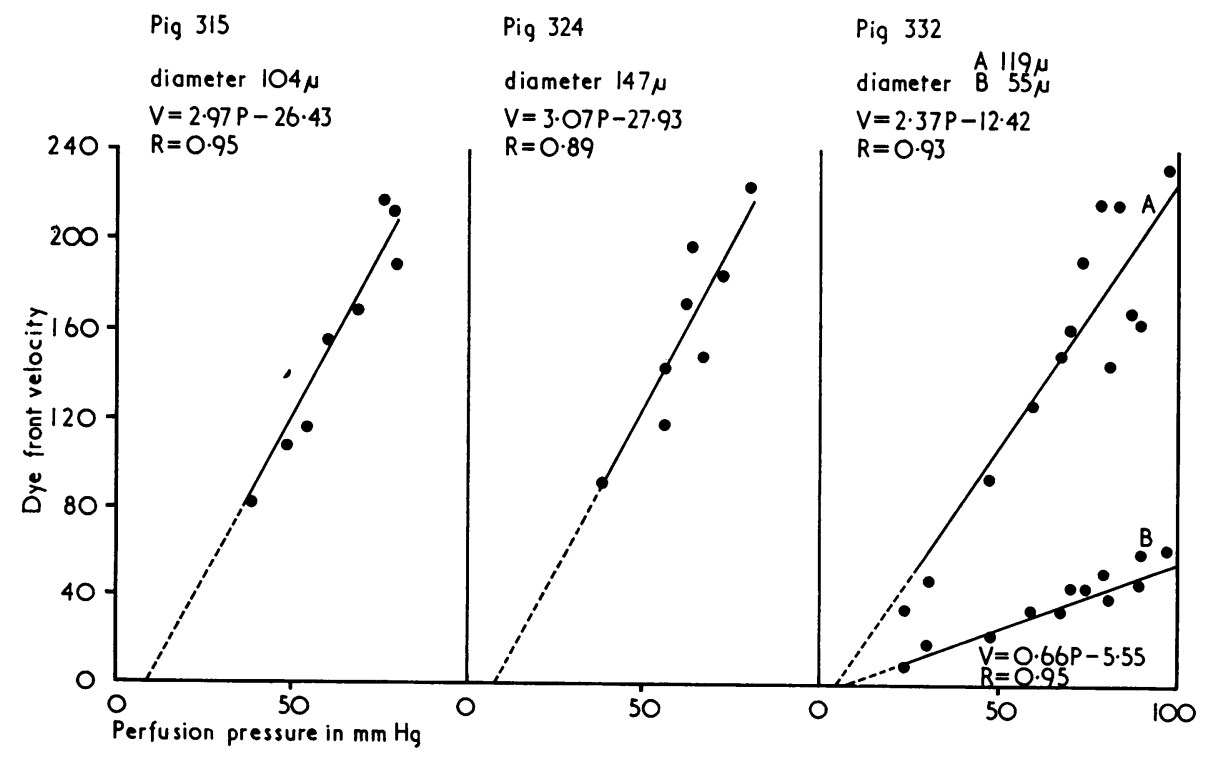

FIG. 2 Relationship between dye front velocity and perfusion pressure in three animals

The point of intersection on the $\mathrm{X}$ axis (the theoretical no-flow point) averaged $8 \mathrm{~mm} . \mathrm{Hg}$. 
(2) Steady state blood flow velocity during raised intraocular pressure

When the intraocular pressure remained raised for more than about I minute, a dilatation of the retinal vessels was observed. This persisted for as long as the raised pressure was maintained. Fluorescein angiograms were performed after 2 minutes of raised pressure. As the perfusion pressure was reduced, a certain level was reached at which the retinal arteries dilated; in the five animals studied, this dilatation occurred when the perfusion pressure fell to an average of $60 \mathrm{~mm} . \mathrm{Hg}$ (representing a fall in perfusion pressure of about 37 per cent.). The mean increase in arterial diameter below this level was 27 per cent. and the results in four arteries (three animals) are shown in Fig. 3.

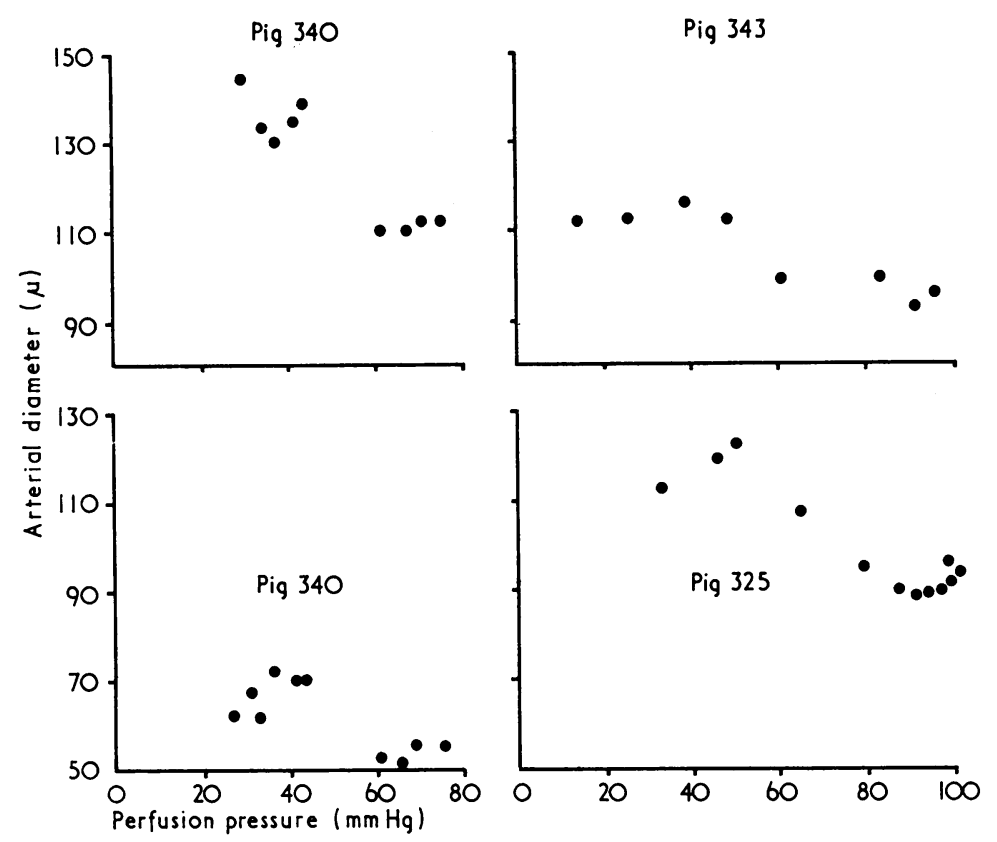

FIG. 3 Relationship between arterial diameter and perfusion pressure in three animals

The dye front velocity had a linear relationship with the perfusion pressure independent of the vessel diameter changes. In these conditions, despite the progressive reduction in blood flow velocity as the perfusion pressure decreased, the dilatation of the arteries maintained the volume flow at near normal levels until the perfusion pressure was reduced by an average of 63 per cent. (average control perfusion pressure $=$ roo per cent.), after which the volume flow fell rapidly as the no-flow point was approached. All five animals studied showed a similar response. Fig. 4 illustrates the results in Pig 325 , showing how the arterial dilatation occurred below a perfusion pressure of $60 \mathrm{~mm} . \mathrm{Hg}$; with an associated preservation of volume flow at normal levels until the perfusion pressure fell below $40 \mathrm{~mm}$. $\mathrm{Hg}$.

If, however, the intraocular pressure was rapidly raised to levels which approached or exceeded the aortic pressure, the retinal vessels did not dilate. Presumably this lack of response was due to the very low transmural pressures in these circumstances. After release of the high intraocular pressure, vessel dilatation was seen-a phenomenon that will be discussed under the heading of reactive hyperaemia.

(3) Pulsatile flow

Visible pulsation of the retinal vessels at normal intraocular pressures was not observed 
Pig 325

Dye front velocity

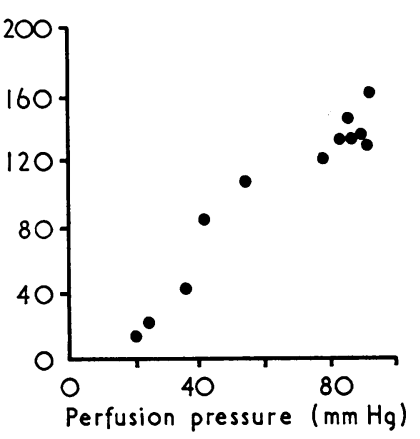

Arterial diameter $(\mu)$

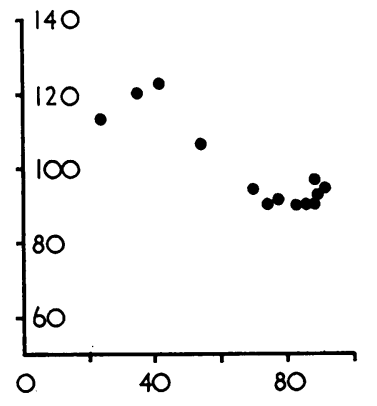

Volume flow

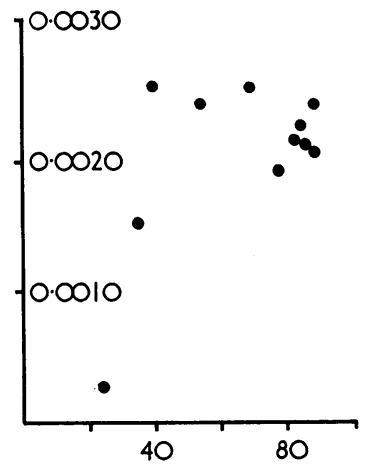

FI G. 4 Relationship between arterial diameter, dye front velocity, volume flow, and perfusion pressure in Pig $32 \vec{\nexists}$

except in the arteries adjacent to the optic disc, where a jerky movement of the vessels was a manifestation of the normal ocular pulse wave. Analysis of the fluorescein dye front a normal perfusion pressure on ciné film taken at 30 frames per second has shown systole diastole differences in velocity (Bulpitt, Kohner, and Dollery, 1973), but the dye front appears to traverse the large retinal arteries in a smooth progression, and previous arteriaf diameter measurements did not demonstrate significant variations in arterial calibre during systole and diastole at normal pressures (Dollery and others, 1968).

In all the experiments in which the perfusion pressure was reduced to low levels, a poin was reached at which pulsation became obvious; this varied from animal to animal an क्षे was a difficult end-point to define, but every animal showed visible pulsatile flow when the aortic diastolic pressure minus the intraocular pressure fell below $17 \mathrm{~mm}$.Hg. At lowe perfusion pressures ciné analysis of the dye front showed a jerky forward motion of the dye्t with the systole/diastole difference increasing as the intraocular pressure was raised. Eventually a point was reached where the forward movement of the dye front ceased i diastole, and thereafter at higher pressures backflow in diastole was observed. As might bड్ expected, when the intraocular pressure exceeded the ophthalmic artery pressure, a retron. grade form of flow resulted with the formation of aggregations of red cells flowing bact towards the disc in a slow granular stream in both arteries and veins. The onset of visible pulsatile flow and the subsequent changes in its form were observed at similar levels of the diastolic pressure in animals with loss of arterial tone caused by papaverine infusions or b. high intraocular pressure. Pulsations were transmitted down to the retinal capillaries although granular flow was seen only in the major vessels.

(4) Reactive hyperaemia

This may be defined as the increase in flow above the control level that occurs if a severe restriction of flow to a tissue is suddenly released. In these experiments, the diameter anf blood flow velocity in the artery under investigation were measured after the sudden reduc tion of a high intraocular pressure; the measurements were compared with the controf values for the vessel at normal intraocular pressures. Studies were carried out in fou animals, and the results are tabulated in Table I. Measurements were taken immediatel after the release of the pressure and related to the previous perfusion pressure.

In reactive hyperaemia the increase in blood velocity was the most constant feature, and was apparently unrelated to the duration of the raised intraocular pressure or to the vesse्d 
Table I Effect of sudden release of high perfusion pressure

\begin{tabular}{|c|c|c|c|c|c|}
\hline \multirow{2}{*}{ Pig no. } & \multirow{2}{*}{$\begin{array}{l}\text { Arterial } \\
\text { diameter } \\
(\mu)\end{array}$} & \multirow{2}{*}{$\begin{array}{l}\text { Duration of perfusion } \\
\text { pressure before release }\end{array}$} & \multicolumn{3}{|c|}{$\begin{array}{l}\text { Per cent. change from control } \\
\text { intraocular pressure studies }\end{array}$} \\
\hline & & & Diameter & Velocity & Volume flow \\
\hline \multirow[t]{2}{*}{315} & 90 & $6 \mathrm{~mm} . \mathrm{Hg}$ for $30 \mathrm{sec}$. & +0 & +101 & + IOI \\
\hline & $8_{5}$ & $6 \mathrm{~mm} . \mathrm{Hg}$ for $30 \mathrm{sec}$. & +5 & $+9 I$ & +100 \\
\hline \multirow[t]{2}{*}{319} & 102 & $-55 \mathrm{~mm} . \mathrm{Hg}$ for I $\mathrm{min}$. & +15 & +52 & +75 \\
\hline & 57 & $-55 \mathrm{~mm} . \mathrm{Hg}$ for I $\mathrm{min}$ & +16 & +40 & +64 \\
\hline \multirow[t]{2}{*}{325} & 88 & $7 \mathrm{~mm} . \mathrm{Hg}$ for $30 \mathrm{sec}$. & +5 & +52 & +60 \\
\hline & 90 & $7 \mathrm{~mm} . \mathrm{Hg}$ for $30 \mathrm{sec}$. & -2 & +64 & +40 \\
\hline \multirow[t]{3}{*}{$33^{2}$} & I 17 & $4 \mathrm{~mm} . \mathrm{Hg}$ for $30 \mathrm{sec}$. & +6 & +80 & +66 \\
\hline & $2 \mathrm{~min}$. later & & +4 & +59 & +55 \\
\hline & $5 \mathrm{~min}$. later & & -3 & -10 & -20 \\
\hline \multirow[t]{3}{*}{$33^{2}$} & 53 & $4 \mathrm{~mm} . \mathrm{Hg}$ for $30 \mathrm{sec}$. & +34 & $+3^{8}$ & +182 \\
\hline & $2 \mathrm{~min}$. later & & +4 & +8 & +22 \\
\hline & $5 \mathrm{~min}$. later & & +0 & +16 & +16 \\
\hline
\end{tabular}

calibre and its degree of dilatation. Increases in blood flow velocity of up to roo per cent. were observed with an average of +64 per cent. in the four animals studied.

During these experiments at very high intraocular pressures no arterial dilatation was seen until the pressure was released. This reactive dilatation depended on the duration of the raised intraocular pressure and occurred only if the high pressure was maintained for more than 30 seconds. The combination of this arterial dilatation and the increased blood flow velocity in the reactive hyperaemic state gave rise to an increase in volume flow over control levels at normal intraocular pressures of up to +182 per cent., with an average of +86 per cent. in the four animals.

Follow-up studies for 5 minutes in Pig 332 showed that the hyperaemia persisted for at least 2 minutes after release of the raised pressure. During these high-pressure experiments no abnormal leakage of fluorescein was noted from the retinal capillaries or larger vessels.

\section{(5) Effect of paracentesis at normal intraocular pressure}

Paracentesis of the anterior chamber was performed in three animals with normal intraocular pressures by puncturing the corneo-scleral margin with a No. I serum needle and allowing the aqueous to escape rapidly. This procedure was followed by considerable distortion of the cornea so that a clear view of the retinal vesseis was not possible. Estimations of the arterial diameter and blood flow velocity, which were made immediately after puncture by fluorescein angiograms, showed that, although there was mechanical distortion of the tissues at the posterior pole, because of the ocular hypotension with retinal folds and accompanying vessel tortuosity, arterial dilatation was not marked-less than 9 per cent. increase in diameter of vessels of about Ioo $\mu$. This was not considered to be a significant dilatation on account of the large errors in measurement resulting from the corneal distortion. Dye front velocity measurements from the angiograms were more 
accurate and showed an average increase in velocity in the three animals of 6 per cen Table II shows the results after paracentesis in the three animals.

Table II Effect of paracentesis

\begin{tabular}{|c|c|c|c|c|}
\hline \multirow{2}{*}{ Pig no. } & \multirow{2}{*}{$\begin{array}{l}\text { Arterial } \\
\text { diameter }(\mu)\end{array}$} & \multicolumn{3}{|c|}{$\begin{array}{l}\text { Per cent. change from control studies } \\
\text { after paracentesis }\end{array}$} \\
\hline & & Diameter & Velocity & Volume flow \\
\hline 324 & 147 & +4 & +7 & +18 \\
\hline $33^{6}$ & 98 & +0 & +10 & +10 \\
\hline 345 & IIO & +8 & $+I$ & +16 \\
\hline
\end{tabular}

Volume flow calculations must be considered in the light of the inaccuracy of vessel diameter measurements, but they show an increase after paracentesis of not more than $\mathrm{r}$ per cent.

(6) Effect of high intraocular pressure on the choroid

At normal intraocular pressures there was an interval of about 0.3 seconds between the first appearance of fluorescein in the choroid and its appearance in the retinal arteries. This choroido-retinal filling time (C-R time) depended on the area of the fundus being examined, being shorter in the region of the disc and longer in the retinal periphery. Choroidal filling occurred segmentally but was completely obliterated at high pressures. In general, a pre longation of the C-R time was observed as the perfusion pressure fell, and Fig. 5 demoig strates this relationship in three animals. Because of the absence of long well-definem sections of choroidal arteries and their rapid obscuration by the filling with fluorescein of the overlying choriocapillaris and retinal circulation, velocity studies on choroidal arteriês were not possible; although in one animal a velocity about 2.5 times greater than that retinal arteries of similar size was observed. In conditions of pulsatile retinal blood flow, the choroidal filling was observed in some animals to show pulsatile features. During reactive hyperaemia the choroid filled rapidly, but its segmental pattern was maintaine and no significant reduction in the C-R time occurred.

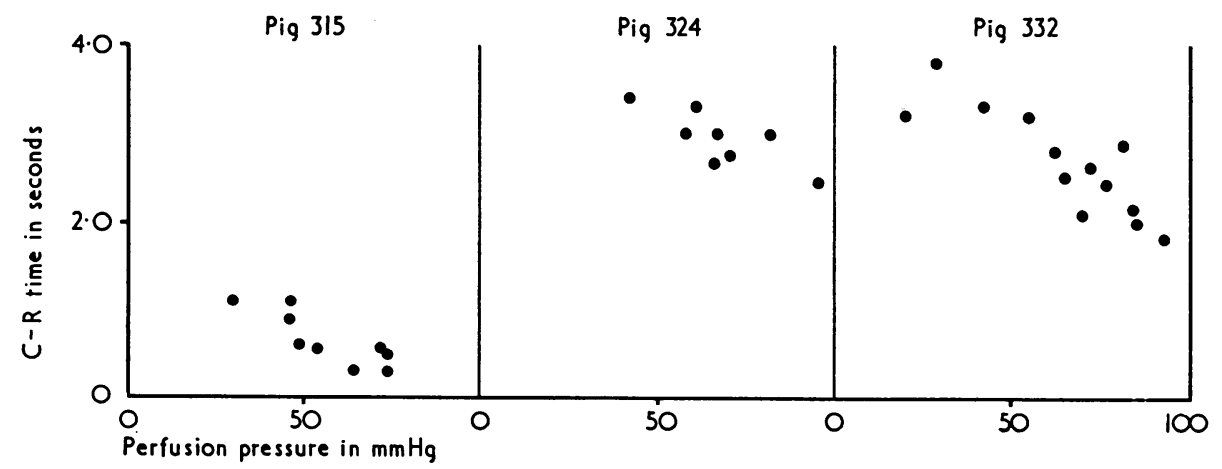

FI G. 5 Changes in choroido-retinal filling time ( $C-R$ time) at different perfusion pressures

(7) Disc changes at high pressures

In several animals a reversible increase in the depth of the disc was observed at high intra ocular pressures. The normal pig optic disc is relatively flat, sometimes with a small centrif 
depression. This central depression was seen to become deeper when the intraocular pressure was raised to very high levels, and stereoscopic photographs confirmed this impression. Quantitative measurement of this phenomenon was not possible.

\section{(8) Magnification changes at high intraocular pressures}

Expansion of the anterior chamber caused by the induced rise in its fluid contents altered the corneal curvature, and thus increased the dioptric power of the eye. This optical effect led to a reduction of the apparent size of objects in the plane of the retina, and when measurements were taken from fixed points in the fundus, such as the edge of the disc or a vessel bifurcation, an increase in linear magnification of $\mathrm{I}$ to 2 per cent. was found when the intraocular pressure was raised from 20 to $80 \mathrm{~mm}$. Hg. These variations were not considered to be significant in the calculations of volume flow changes.

\section{Discussion}

These experiments illustrate two basic responses of the retinal circulation to alterations in the perfusion pressure. The retinal blood flow velocity, as measured by the advancement of the dye front in fluorescein angiography, decreased proportionately to the reduction in perfusion pressure, irrespective of the state of the retinal arteries. In the artificial situation, velocity measurements were taken at raised intraocular pressures before dilatation of the arteries occurred, and Fig. 2 shows that extrapolation of the perfusion pressure/velocity graph gives a theoretical no-flow point of $8 \mathrm{~mm} . \mathrm{Hg}$. This could represent the pressure drop between the aorta and the retinal artery plus the intraluminal critical closing pressure required to keep the vessel open (Burton, 1962).

In the steady state situation, the retinal vessels adapted to the raised intraocular pressure and the reduction in blood flow velocity was compensated for by an increase in arterial diameter. Dilatation was seen to occur when the perfusion pressure was reduced to an average of $60 \mathrm{~mm} . \mathrm{Hg}$, representing a 37 per cent. reduction of the control perfusion pressure. This arterial dilatation, which was about 27 per cent., was presumably related to ischaemia caused by the lowered perfusion pressure giving rise to hypoxia, $\mathrm{CO}_{2}$ retention, and the accumulation of metabolites. This autoregulation was sufficient to preserve a normal volume flow until the perfusion pressure was reduced by an average of 63 per cent.

Arterial dilatation, however, was governed not only by the effect of reduced perfusion pressure but also by the speed at which high intraocular pressures were reached. When sudden rises of intraocular pressure at or above the aortic pressure were produced, arterial dilatation did not occur until after the release of the high pressure, possibly because the smooth muscle in the arterial wall could not relax when the transmural pressure was very low. After the release of the high intraocular pressure, there was dilatation of the arteries and a substantial increase in blood flow velocity with an average increase in volume flow of +86 per cent. This reactive hyperaemia persisted for several minutes and a similar increase appeared to occur concomitantly in the choroid.

In the clinical situation sudden elevations and reductions of the intraocular pressure can be achieved by firm digital massage of the globe - a manoeuvre which has been used to reduce the intraocular pressure in cases of retinal artery obstruction. The results of these experiments, admittedly in normal anaesthetized animals with no underlying arterial disease, suggest that this method of compression/decompression can give rise to large increases in retinal blood flow through reactive hyperaemia, changes of up to +182 per cent. having been recorded. 
The failure of paracentesis to produce comparable increases in volume flow is not surprising in eyes with normal intraocular pressures. The improvement in perfusion pressure as a result of allowing aqueous to escape and thereby reducing the intraocular pressure to zero, amounts to less than + ro per cent and, although accurate measurements of volume. flow changes were not possible, the increase was not likely to be more than +18 per cent. The change in volume flow after paracentesis did not therefore compare favourably in these experiments with the increases seen in reactive hyperaemia after compression/decompression manoeuvres. Furthermore, after removal of the paracentesis needle the intraocular \& pressure rapidly recovered so that the possible beneficial effects were short-lived.

The observation of "herniation" of the optic disc tissues at high intraocular pressures indicates a laxity of the lamina cribrosa in these young animals which can give rise to reversible disc cupping without loss of prelaminar tissue. This interesting finding supports the clinical impression that certain types of disc cupping in infants are reversible-and presumably related to the elasticity of the neonatal laminar tissue.

\section{Summary}

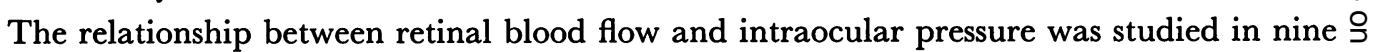
healthy young pigs. Despite a progressive decrease in the blood flow velocity as the intraocular pressure was raised, the volume flow through the retinal circulation was maintained at near normal levels until the perfusion pressure was reduced by an average of 63 per cent. $\vec{\epsilon}$ This preservation of volume flow was produced by dilatation of the retinal arteries. Further increases in the intraocular pressure led to a rapid decrease in flow and the theoretical noflow point in the retinal arteries was calculated to be $8 \mathrm{~mm} . \mathrm{Hg}$.

After sudden reduction of intraocular pressure after a period of elevation, volume flow was increased by an average of 86 per cent. through reactive hyperaemia. Reduction of normal intraocular pressure by paracentesis did not increase blood flow by more than $20 \stackrel{\circ}{\Rightarrow}$ per cent. These comparisons suggest that compression/decompression of the globe is likely to be substantially more effective in improving volume flow than aqueous puncture.

Reversible cupping of the optic disc was observed at high intraocular pressures.

We wish to acknowledge the help given in these experiments by Mr. M. Tudball and the technical staff of the Department of Clinical Pharmacology, Royal Postgraduate Medical School, Hammersmith Hospital. We are indebted to Mr. T. Tarrant and the Audiovisual Department, Institute of Ophthalmology, for the illustra- $\exists$ tions, and we are grateful to Miss Josephine Lace and Mrs. M. Overland for secretarial assistance.

\section{References}

blumenthal, M., Best, M., and galin, м. (197I) Amer. J. Ophthal., 71, 819

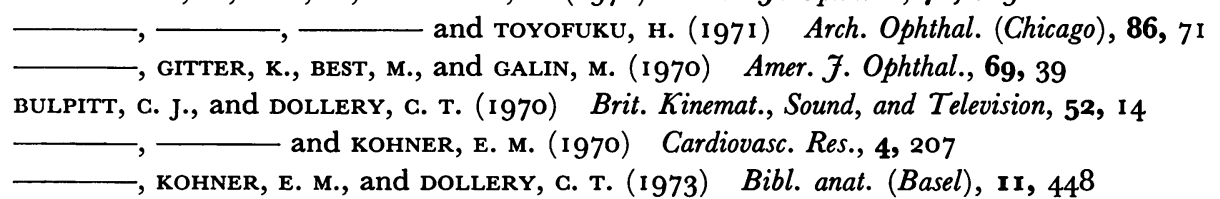

Burton, A. G. (I 962) "Handbook of Physiology", ed. W. F. Hamilton, Section 2, Girculation:

vol. I, p. 85. American Physiological Society, Washington, D.C.

Dollery, c. T., Henkind, P., KoHNer, E. M., and PATERson, J. W. (1968) Invest. Ophthal., 7, I9I

FFYTCHE, T. J., BULPITT, C. J., ARGHER, D., KOHNER, E. M., and DOllery, c. T. (I973) Brit. J. Ophthal.,

57, 910

goldmann, H., and BLok, P. (1970) v. Graefes Arch. klin. exp. Ophthal., 183, 232

HAYREH, s. s. (1969) Brit. J. Ophthal., 53, 72 I

(1970) Ibid., 54, 289

ROOTMAN, J. (I97 I) Ibid., 55, 808

SWietliczko, I., and DAvid, N. (I970) Amer. 7. Ophthal., 70, 35I 